\title{
A NOÇÃO DE ATITUDE ESTÉTICA EM SIMONE DE BEAUVOIR
}

\section{THE NOTION OF AESTHETIC ATTITUDE IN SIMONE DE BEAUVOIR}

Lucas Joaquim da Motta ${ }^{1}$

(lucasjoaquimdamotta2000@gmail.com)

\begin{abstract}
RESUMO
Simone de Beauvoir (1908-1986), em Por uma moral da ambiguidade (2005 [1947]) e especificamente no tópico intitulado "A atitude estética", dedicou-se a pensar uma concepção de estética através da definição existencialista de liberdade. A liberdade, como um movimento humano original, é o que permite ao sujeito descobrir as razões de seus próprios atos; assim, uma atitude estética pretende afirmar qualquer obra de cunho estético (seja por exemplo um livro literário, uma pintura ou uma escultura) como um dado que o criador, isto é, aquele que escreve, pinta ou esculpe, tentará justificar enquanto for matéria da própria obra produzida. Ainda assim, a atitude estética apenas é possível se houver uma temporalidade, e o presente será o elemento fundamental para que tal ato seja praticado. Portanto, neste artigo objetiva-se discutir introdutoriamente o modo como Beauvoir abordou certa concepção de estética com base no movimento autêntico do homem em direção à liberdade.
\end{abstract}

Palavras-chave: Atitude Estética. Beauvoir. Engajamento. Liberdade.

\begin{abstract}
Simone de Beauvoir (1908-1986) in For a moral of ambiguity (2005 [1947]), specifically in the topic entitled "The aesthetic attitude", devoted herself to thinking a conception of aesthetics through the existentialist definition of freedom. Freedom, as an original human movement, is what allows the subject to discover the reason for their own actions; thus, an aesthetic attitude intends to affirm any work of aesthetic nature (such as a literary book, a painting or a sculpture) as a fact that the creator, that is, the one who writes, paints or sculpts it, will try to justify as long as such creator is a matter of the work produced. Still, the aesthetic attitude is only possible if there is a temporality, and the present will be the fundamental element for such an act to be practiced. Therefore, this article aims to discuss in an introductory way how Beauvoir approached a certain conception of aesthetics based on the authentic movement of man towards freedom.
\end{abstract}

KEYWORDS: Aesthetic Attitude. Beauvoir. Engagement. Freedom.

\section{INTRODUÇÃO}

\footnotetext{
${ }^{1}$ Graduando em Filosofia pela Universidade Federal de São Carlos (UFSCAR).

CV Lattes: http://lattes.cnpq.br/3740493609654132.

ORCID: https://orcid.org/0000-0003-4697-6247.
} 
Parece-nos tarefa árdua pensar uma noção original de estética em Simone de Beauvoir, tendo em vista que a presença de um ideal artístico é, em uma primeira leitura, obscura na obra da autora. Para iniciarmos essa investigação, partiremos da relação interpessoal dos seres humanos e de seu engajamento no mundo em busca de superarem a si mesmos; tal relação nos direciona a uma compreensão peculiar sobre os atos humanos que possui sua raiz teórica na concepção beauvoiriana de liberdade. Através de um mundo constituído unicamente por sujeitos particulares e separados entre si, a palavra "liberdade" recebe um conteúdo concreto em sua definição. Dado que uma atitude estética apenas será exequível se o sujeito, antes de qualquer coisa, buscar desvelar o mundo que ele próprio funda por meio de sua condição - a saber, a condição de liberdade -, podemos compreender que há uma correlação entre o movimento de liberdade engajada exercida pelo ser humano e o ato estético.

Todos os sujeitos existentes no mundo são livres. Assim, a liberdade deles se vê em direção à liberdade de outrem, gerando certo engajamento o qual permite que cada objeto seja atingido por significações humanas. E o que pretendemos demonstrar com isso? Em primeiro lugar, o que Simone de Beauvoir está defendendo, e isto é um aspecto fundamental do ensaio Por uma moral da ambiguidade, é que o contato direto entre a liberdade singular do sujeito e a liberdade de outrem torna possíveis todos os juízos que tais sujeitos extraem da realidade que eles próprios fundam. Para que esse ato de engajamento seja realizado, é preciso que o sujeito enquanto tal esteja situado no mundo que ele próprio desvela, isto é, no mundo em que se lança como pura existência, por exemplo o conjuncias $i$. Essas são duas ideias importantes que devem estar claras para se desvelarem tanto sua condição quanto sua existência.

O desvelamento do mundo é possível, entre outras coisas, graças ao paradoxo das relações entre vida e morte, amor e ódio, revolta e resignação; não obstante, é preciso entender que a liberdade não é um dado estabelecido, e sim algo a ser conquistado através de um movimento original. Nessas condições, a expressão "querer-se livre" (BEAUVOIR, 2005, p. 64, grifo da autora), utilizada por Simone de Beauvoir inúmeras vezes no ensaio em questão, sugere-nos que a liberdade deve ser buscada a todo instante; portanto, "ela [a liberdade] jamais é realizada, é preciso que ela se realize incessantemente" (BEAUVOIR, 2005, p. 27, grifos da autora). Num movimento criador, todas as significações e todos os valores são fundados no mundo.

Desse modo, o sujeito - enquanto matéria da obra fundada por ele mesmo se encontra numa situação cujo intuito não é contemplar o mundo ao qual ele pertence, mas agir em nome de um projeto definido que permitirá qualquer 
justificação do ato estético. Uma atitude estética em Beauvoir comportará em seu cerne, ou seja, em seu núcleo reflexivo, o fazer-se do sujeito como investigação imparcial sobre todas as situações humanas que estão ao seu redor. Em suma, tal fazer-se é realizável devido à busca do sujeito pela liberdade. Ao realizar esse movimento, o ato humano é preenchido por um conteúdo concreto, isto é, torna-se repleto de significações fundadas por intermédio de um movimento operante: a própria liberdade.

\section{A LIBERDADE COMO MOVIMENTO ORIGINAL HUMANO}

A problemática da liberdade em Simone de Beauvoir é tão polêmica quanto o dualismo ontológico cartesiano para os pensadores modernos. Isso porque, em Beauvoir, a concepção de liberdade surge como fonte de significações e valores que justificam toda a existência humana. Trata-se de uma condição original do sujeito. Tal sujeito, antes de qualquer coisa, deve querer buscar sua própria liberdade, pois é através dela que o projeto humano é fundado e o ato estético torna-se exequível; portanto, sem a liberdade e sem o contato entre as liberdades singulares, a existência não pode ser fundada. Para a autora, em linhas gerais, a busca pela liberdade ocorre em um movimento temporal, pois a unidade de tal liberdade carrega em si o distanciamento do passado rumo a um futuro indefinido. Desse modo, a síntese temporal nos revela um aspecto da busca pela liberdade: o tempo opera para que tal busca seja possível, sobretudo tendo-se em vista como esse movimento se relaciona com o conceito beauvoiriano de presente.

Ora, mas então o que seria o presente nessa jogada? O termo "presente" possui um sentido inerente em Beauvoir, pois "ele [o presente] não é um passado em potência" (BEAUVOIR, 2005, p. 66), mas é “o momento da escolha e da ação” (BEAUVOIR, op. cit.). Em outras palavras, o presente não é, na definição clássica da palavra, uma passagem do passado, mas um desdobramento humano que resulta na ação. A ação - aquilo que afirma a transcendência humana ao fazer com que o sujeito se lance rumo a uma finitude desconhecida - faz com que o sujeito funde seu próprio presente, isto é, seja responsável por todas as situações por ele criadas. Em termos beauvoirianos

O artista não poderia desinteressar-se das situações dos homens que o cercam. Em outrem está engajada sua própria carne. Lutarei, portanto, para que homens livres deem a meus atos, a minhas obras, seu lugar necessário. (BEAUVOIR, 2005, p. 198, grifo nosso) 
Dessa forma, o artista, enquanto idealizador da realidade na qual está inserido, em hipótese alguma se separa das situações em que seres humanos estão envolvidos, pois é graças ao entrelaçamento delas que poderíamos pensar certo engajamento que possibilite a superação do ser humano em relação aos outros seres humanos através da liberdade.

Um dos fundamentos para se buscar a realização da liberdade é a escolha e, em relação ao passado, a escolha não é mais possível. O sujeito, portanto, passa de uma situação para outra incessantemente. Nesse sentido, vemos que o presente é caracterizado por Simone de Beauvoir como o instante da escolha, ou seja, o momento em que a ação é escolhida e a situação é fundada

Não se poderia justificar tudo o que é com a afirmação de que tudo pode também ser objeto de uma contemplação, uma vez que o homem jamais contempla: ele $f a z$. (BEAUVOIR, 2005, p. 66, grifo nosso)

A atitude estética consiste em um fazer-se sem qualquer juízo prévio; o sujeito que pratica tal atitude não contempla o objeto observado, mas o faz conforme lança seu olhar sobre o mundo que ele próprio funda. Logo, tal atitude apenas pode ser afirmada conforme o projeto ${ }^{2}$ humano é definido e as situações humanas são diferenciadas. O presente faz com que o sujeito se projete no mundo, cujas situações são fundadas, e o ato é preenchido por um conteúdo concreto.

Porém, como veremos mais adiante, é necessário o distanciamento entre o sujeito e sua situação para que a reflexão acerca do mundo seja imparcial. Desse modo, é na relação do sujeito com outrem que qualquer manifestação do ato recebe um lugar, um sentido real no mundo. $\mathrm{O}$ artista extrai das situações, sejam ela particulares ou alheias, um ato original que traz consigo a vivência humana para o presente. Por isso, toda atitude estética em Beauvoir é estabelecida por uma relação dos seres humanos entre si e com o tempo, pois apenas com base nessa relação a noção de arte pode ser esboçada.

Com base nisso, é necessário negar que qualquer ato estético esteja distante da produção humana. Logo, qualquer manifestação artística, como a pintura de um quadro, a composição de uma partitura de piano e o esboço de um movimento a ser realizado por uma bailarina, é original

\footnotetext{
${ }^{2}$ Para clarificar introdutoriamente como o projeto é caracterizado por Simone de Beauvoir, atentemonos ao que a própria autora escreveu: “[...] o projeto é singular e, portanto, infinito: a dimensão temporal da transcendência é desejada por si mesma: depende da natureza do objeto fundado [...]. O homem busca recuperar seu ser, mas sempre pode novamente transcender este objeto no qual sua transcendência está engajada" (BEAUVOIR, 2005, p. 168). Para Beauvoir, o sujeito se projeta num objeto e, com razão, extraem-se juízos e significações que o próprio sujeito lhe impõe. Por fim, a transcendência do sujeito no mundo é realizada por intermédio de um movimento engajado, isto é, a liberdade, e as situações humanas são superadas.
} 
e pertence inteiramente ao ato humano. Deve-se reconhecer que a arte é feita pelo e para o ser humano. Contudo, uma manifestação artística não se entrelaça necessariamente com certa situação pela qual o ser humano está englobado.

Em vista disso, essa mesma manifestação não precisa superar ou corresponder a algum anseio que esteja correlacionado com a produção do artista. Justamente por esse motivo, qualquer atitude estética se relaciona com um processo temporal, sendo que a ação artística naturalmente se desprende do passado e lança a si mesma num movimento criador. Em novos termos, a atitude estética inventa a obra por meio da própria liberdade; desse modo, o sujeito que exerce um ato estético, segundo Beauvoir, distancia-se dos outros sujeitos e se coloca diante da história "como um puro olhar" (BEAUVOIR, 2005, p. 65). É através desse olhar puro que as situações humanas são igualadas e a atitude estética apreende as coisas pela "indiferença [das situações] de suas diferenças" (BEAUVOIR, op. cit.).

A indiferença entre as situações humanas é afirmada através de um projeto definido, visto que "o criador projeta na obra de arte um dado que ele justificará enquanto matéria dessa obra" (BEAUVOIR, 2005, p. 66, grifos nossos). Sendo assim, qualquer manifestação da obra estética, como a representação da miséria ou da cólera num quadro, pode ser justificada pelo artista independentemente de suas vivências ou de seus olhares perante o mundo de que ele desvela a existência.

\section{A ALEGRIA DESINTERESSADA PELAS SITUAÇÕES HUMANAS}

Vimos até agora que o sujeito se lança rumo a um futuro indefinido que ele próprio terá de desvendar através de uma fonte original: tal fonte é a liberdade. Assim, para pensarmos qualquer valor estabelecido entre os seres humanos, será necessário retornar a essa concepção beauvoiriana de liberdade. O sujeito que adota qualquer atitude estética se desprende das situações em que todos os outros sujeitos estão envolvidos, para assim não ter nenhuma relação com o mundo senão a de criador da obra. Isso foi o que Simone de Beauvoir denominou “contemplação desinteressada" (BEAUVOIR, 2005, p. 64).

"Situação" é um conceito de extrema importância aqui, porque carrega em si o interesse humano de agir-no-mundo, mas sem se debruçar com parcialidade no mesmo mundo. Nessa perspectiva, o sujeito apenas se situa ao realizar sua projeção em tal mundo e, em vista disso, todos os outros sujeitos também se situam. Surge-nos uma questão: como pode haver uma relação entre parcialidade e situação ao mesmo tempo? 
Em primeiro lugar, segundo Beauvoir, a situação é caracterizada pela transcendência do sujeito através de um ato concreto. O sentido do ato é realizado somente pelo sujeito que atua no mundo que ele próprio funda e, com razão, desvela; logo, a situação carrega em si a projeção do sujeito rumo a uma nova situação, ou seja, a uma situação que é consecutiva à anterior. Desse modo, as situações são superadas através da transcendência - em sentido ontológico -, havendo entre elas uma relação concreta.

A parcialidade, por sua vez, exerce o olhar humano perante a história enquanto processo temporal. Com base nisso, a observação do mundo de maneira imparcial permite que as situações sejam igualadas e que qualquer preferência seja abolida do mundo observado. Nessa perspectiva, o sujeito que opera em direção a tal mundo se desprende, ou seja, suspende qualquer juízo, fazendo-se como espectador e protagonista (veremos isso com mais clareza nas próximas linhas) da situação à qual está circunscrito. Ao realizar esse movimento, tal sujeito funda o mundo, que, por sua vez, torna-se expressivo, do mesmo modo que, por exemplo, Claude Monet, pintor francês do século XIX, fez a tela Mulheres no jardim ${ }^{3}$. Ao buscar a liberdade, o sujeito em questão realiza um ato que objetiva a apreensão que ele próprio faz das situações ocorridas no plano da facticidade ${ }^{4} ; \operatorname{logo}$, esse ato será a atitude estética.

Mas por que Beauvoir se referiu, como dito anteriormente, à atitude estética como "contemplação desinteressada" (BEAUVOIR, 2005, p. 65)? O sujeito, ao se distanciar - no sentido metafórico da palavra - do mundo e se colocar como puro olhar perante as coisas que estão ao seu redor, estará contemplando-as, isto é, abstraindo-as para ampla reflexão. Toda essa visão implica uma abolição dos olhares que possuem alguma preferência humana. Assim, a atitude estética terá de ser desinteressada das situações em que os sujeitos estão inseridos para que um olhar impessoal, fora do tempo, alcance da mesma maneira tanto os antigos templos das cidades japonesas como as fábricas abandonadas e destruídas pelo passar do tempo na crise econômica de 1929

\footnotetext{
${ }^{3}$ Tela pintada em 1886. Nela encontramos a presença de três mulheres vestidas com roupas brancas ao redor de uma árvore; uma delas está acompanhada de um rapaz que aparenta ser um amigo ou um namorado. O pintor impressiona o espectador, pois, para retratar as três pessoas que estão do lado esquerdo da obra, ele se utilizou de seu olhar sobre sua companheira, Camille Doncieux. Em hipótese alguma podemos buscar alguma semelhança entre as expressões de tais figuras, no caso, as três pessoas, com os retratos de Camille, pois Monet os fez conforme seu olhar, ou seja, sua perspectiva única e singular, acerca da companheira.

${ }^{4} \mathrm{O}$ conceito de facticidade é polêmico na história da filosofia contemporânea, sobretudo em pensadores como Edmund Husserl, Martin Heidegger, Maurice Merleau-Ponty, Jean-Paul Sartre e Simone de Beauvoir. Sendo assim, não nos deteremos em tal conceito, mas apenas o clarificaremos. Grosso modo, considere-se a facticidade como sendo o plano no qual o sujeito se coloca frente ao mundo que desvela e em que os atos são preenchidos concretamente. O sujeito fático, portanto, deve sempre superar a si mesmo e a outrem para que o ato receba um sentido único e concreto.
} 
Assim, o amador de obras históricas assiste com a mesma paixão serena ao nascimento e à derrocada de Atenas, de Roma, de Bizâncio; o turista considera com a mesma tranquila curiosidade a arena do Coliseu, os Latifundia de Siracusa, as termas, os palácios, os templos, as prisões, as igrejas: essas coisas existiram, isso basta para satisfazê-lo. (BEAUVOIR, 2005, p. 65)

Aquele que atua em relação ao mundo cujo indivíduo ${ }^{5}$ transcende a si mesmo tende a eliminar qualquer diferença capaz de julgar os acontecimentos que decorrem desse mesmo mundo. Trata-se daquele que pratica a atitude estética.

Como a própria Beauvoir previu, apenas o fato de as coisas existirem já basta para satisfazer o amante da estética. O ato estético observa e analisa todas as coisas existentes no mundo com perfeita imparcialidade, isto é, sem nenhuma preferência por isto ou aquilo. Nessa perspectiva, o artista capta as figuras que a história criou e as projeta através de um movimento engajado e criador, ou seja, a liberdade.

Mas Beauvoir nos faz uma ressalva curiosa para compreendermos tal imparcialidade. Deve-se observar que uma atitude imparcial acerca dos fatos mundanos aparece nos momentos de total desânimo e desespero do ser humano, pois esse é um dos modos de o indivíduo enquanto "sujeito soberano e único no meio de um universo de objetos" (BEAUVOIR, 2005, p. 14) - fugir à verdade do presente. Contudo, fugir à verdade do presente não implica negá-lo, tampouco afirmá-lo como uma mentira, mas sim desprender-se das situações do presente para que qualquer preferência seja abolida e a obra seja analisada puramente como algo que se faz através de uma apreensão imparcial. Esse seria o lançamento do indivíduo ao mundo, como dito anteriormente, para que ele se coloque como "puro olhar" diante de todas as coisas.

Em tese, a atitude estética, como ato temporal, está totalmente relacionada com a concepção beauvoiriana de presente, porque é um modo de o sujeito distanciar-se, refugiar-se de sua condição humana - o que se dá no instante da vida - e, com efeito, colocar-se diante do mundo como personificação imparcial acerca daquilo que compõe tal mundo. A expressão "puro olhar" (BEAUVOIR, 2005, p. 65), utilizada pela própria Simone de Beauvoir para se referir à ideia de uma atitude estética, é curiosa aqui, já que carrega em sua definição o conceito de liberdade. Veremos isso com mais clareza nas linhas seguintes.

\footnotetext{
${ }^{5}$ O termo “indivíduo” possui uma definição própria em Simone de Beauvoir. Grosso modo, podemos considerar como indivíduo o "sujeito soberano e único no meio de um universo de objetos" (BEAUVOIR, 2005, p. 14). Portanto, é o sujeito que se faz no mundo da facticidade, isto é, no mundo cujo ser humano se afirma como tal e funda seus projetos. Essa será a definição de indivíduo que adotaremos aqui.
} 


\section{A ATITUDE ESTÉTICA COMO "PÔR-SE FORA"}

A tarefa de realizar a atitude estética mediante uma liberdade criadora se apresenta como um fazer-se no tempo; portanto, devemos pensar a ação como algo que se faz no tempo através da liberdade. Em outras palavras, a ação constrói e, ao mesmo tempo, participa da liberdade.

As subdivisões do tempo, isto é, passado, presente e futuro, também foram investigadas por Simone de Beauvoir. Em relação ao passado, nenhuma ação é mais possível; os eventos que ficaram no passado, como a guerra e a traição, nada mais têm senão o fato de terem acontecido, o que indica que os seres humanos podem impedir a recaída ou permitir a volta de todos os eventos já ocorridos. Eles carregam a demonstração concreta do contato da liberdade singular com a liberdade de outrem, de modo que a existência estética se relaciona com o passado a partir do momento em que a história é construída e o mundo se torna expressivo.

Seguindo esse raciocínio, o futuro está a construir-se a todo momento; logo, ele tem a nos oferecer a ansiedade pela busca do desvelamento do mundo. $\mathrm{O}$ futuro se manifesta como um engajamento que permite sua idealização. Quando, por exemplo, um pintor cria uma obra que demonstra uma perspectiva lançada ao futuro e que não nos remete ao presente, seu olhar já está nesse futuro indefinido; o sujeito se projeta rumo ao futuro desconhecido que ele próprio cria por intermédio de sua liberdade engajada.

Mas o que nos interessa aqui é o conceito de presente, pois ele se apresenta como o instante e, com base nele, o sujeito consegue colocar seu olhar para fora, isto é, no mundo que funda. Em outras palavras, trata-se de um movimento centrífugo, pois parte da interioridade rumo ao universo. O praticante do ato estético se projeta naquilo com que entra em contato e gera significações acerca do que apreendeu

[...] não há projeto que seja puramente contemplativo, uma vez que sempre nos projetamos em alguma coisa, no futuro; pôr-se "fora" é ainda uma maneira de viver o fato inelutável de que se está dentro; aqueles dos intelectuais franceses que pretendiam, em nome da história, da poesia ou da arte, dominar o drama da época, querendo ou não, eram os seus atores, e faziam mais ou menos explicitamente o jogo do ocupante. Da mesma maneira que o esteta italiano ocupado em acariciar os mármores e os bronzes de Florença desempenha por sua própria inércia um papel político na vida de seu país. (BEAUVOIR, 2005, p. 66)

O indivíduo se torna protagonista da própria arte, de tal modo que ele mesmo se coloca diante da história como puro olhar. Em hipótese alguma ocorre o 
desprendimento desse mesmo indivíduo em relação ao mundo. A projeção do sujeito rumo a um futuro faz com que as situações humanas se tornem indiferentes, resultando, assim, num ato imparcial em direção àquele mundo.

Vê-se, portanto, que o sujeito enquanto artista se torna protagonista da obra que ele próprio funda; porém, as significações extraídas da obra fundada não possuem um sentido único. Utilizando-nos do exemplo que a própria Simone de Beauvoir nos fornece: um escritor "queria nos transmitir o horror que lhe inspiram as prisões para crianças", mas "ele conseguiu um livro tão bonito que, encantados pela narrativa, pelo estilo, pelas imagens, esquecemos o horror da prisão ou até nos surpreendemos admirando-a" (BEAUVOIR, 2005, p. 66-67).

Assim, a atitude estética não se apresenta como uma definição estabelecida pela autora; a atitude estética, é, dentre outros, um método de ser, cujo limite é paradoxal. Em novos termos, ela é um dos caminhos que preenchem os atos humanos com um conteúdo que deve ser conquistado através da busca do sujeito pela liberdade. O presente é o momento da ação, e esta, por sua vez, forma uma correlação com a liberdade. Em suma, a atitude estética encontra-se no cerne da existência humana, e ela se manifesta fazendo com que o artista, isto é, o praticante de tal ato, torne-se ao mesmo tempo protagonista e espectador do mundo em que está situado a fim de conferir sentido ao ato.

Simone de Beauvoir nos apresenta uma correlação entre o sujeito que pratica a atitude estética e o mundo que se torna expressivo conforme é atingido pelas significações humanas. Essa correlação pode ser explicada através de duas noções, a saber: (1) o sujeito que pratica a atitude estética, isto é, o artista, situa-se no mundo e preenche com significações aquilo com que ele próprio entra em contato; e (2) o mundo se torna expressivo conforme recebe tais significações do artista, sendo que tal recebimento é possível graças ao movimento autêntico do ser humano, ou seja, a liberdade.

Assim, as significações são fundadas por intermédio da liberdade engajada que, por sua vez, é temporal e própria ao sujeito que opera no mundo. No desenrolar desse engajamento, as razões de agir são descobertas. Enfim

Para que o artista tenha um mundo a expressar, é preciso primeiro que ele esteja situado nesse mundo, oprimido ou opressor, resignado ou revoltado, homem entre os homens. Mas então ele encontra no cerne de sua existência a exigência comum a todos os homens; é preciso que ele queira a liberdade em si e universalmente; é preciso que tente conquistá-la: à luz desse projeto as situações se hierarquizam e razões de agir se descobrem. (BEAUVOIR, 2005, p. 67) 
Em suma, os objetos que compõem o mundo são atingidos por significações, e nesse mesmo mundo a liberdade - pressuposto fundamental da condição humana - recebe um conteúdo concreto. Nessa perspectiva, os atos humanos desvelam o mundo que se funda a todo momento em vista de um "desvelamento ulterior" (BEAUVOIR, 2005, p. 64); logo, é ao ocorrer o contato direto entre as liberdades singulares que tal mundo recebe, como dito anteriormente, um sentido.

Contudo, mesmo que o sujeito esteja situado nesse mundo onde desvela sua existência, isso não significa que o ato estético exige um interesse particular; muito pelo contrário, tal ato apenas se torna realizável se o artista abolir todas as preferências acerca desse mesmo mundo e, com razão, observá-lo com uma "visão impessoal” (BEAUVOIR, 2005, p. 65), isto é, sem nenhum juízo estabelecido sobre os objetos fundados por intermédio do ato estético.

\section{CONSIDERAÇÕES FINAIS}

Ao desenvolvermos este trabalho, que tinha por finalidade abordar como Simone de Beauvoir esboçou um conceito geral de atitude estética, pudemos notar que tal conceito carrega em si duas noções fundamentais, a saber: a noção de liberdade e a noção de tempo, sobretudo o presente.

A liberdade singular - sendo ela engajada em direção às outras liberdades singulares permite que todos os objetos e situações presentes no mundo sejam atingidos por significações humanas e recebam um conteúdo concreto. O tempo, por sua vez, forma uma correlação com a liberdade, pois faz com que o artista seja, ao mesmo tempo, o criador e o protagonista de suas realizações. Desse modo, o que caracteriza tal artista é o fato de ele não contemplar o mundo ou aquilo que apreende, mas sim fazê-lo.

A atitude estética terá como objetivo último o expressar-se do mundo; em outras palavras, ele "é um mundo falante"6 (BEAUVOIR, 2005, p. 64). É necessário que o artista se situe nesse mundo para que as significações de seu olhar o atinjam. A história, como passado, precisa ser confirmada, e a imparcialidade perante todas as coisas, como ato do presente, deve ser assumida.

\footnotetext{
${ }^{6}$ Essa expressão é curiosa e aparece somente uma vez no ensaio em questão. Simone de Beauvoir, ao escrevê-la, referia-se ao fato mundo: conforme é atingido por significações humanas, ele torna-se expressivo; portanto, ele (o mundo) faz com que os apelos e as solicitações humanas sejam elevados. Em outras palavras, é como se tal mundo, ao receber as ações humanas, refletisse-as em direção ao sujeito como resposta imediata. Em novos termos, o mundo torna-se expressivo.
} 
Portanto, a atitude estética é uma das maneiras de o sujeito buscar a liberdade através da imparcialidade de seu olhar sobre o mundo, uma vez que tal imparcialidade significa a suspensão de todos os juízos sobre esse mundo. Com razão, através desse movimento o conteúdo do ato estético é criado e o mundo torna-se expressivo; mas tal atitude exige a personificação do sujeito em um movimento de pôr-se para fora, fazendo com que seja protagonista da própria criação. Logo, a existência do sujeito que se faz como artista e dos objetos fundados no mundo por ele mesmo - no sentido beauvoiriano do termo - basta para satisfazê-lo. 


\section{REFERÊNCIAS BIBLIOGRÁFICAS}

BEAUVOIR, S. O existencialismo e a sabedoria das nações. Lisboa: Minotauro, 1964. (Coleção Ensaio)

Por uma moral da ambiguidade. In: Por uma moral da ambiguidade. Rio de Janeiro: Nova Fronteira, 2005.

. Pirro e Cinéias. In: Por uma moral da ambiguidade. Rio de Janeiro: Nova Fronteira, 2005.

DIAS, J. A. O. Ambiguidade e liberdade na filosofia moral de Simone de Beauvoir. 2016. 97f. - Dissertação (Mestrado) - Universidade Federal do Ceará, Programa de PósGraduação em Filosofia, Fortaleza-CE, 2016. Disponível em: <http://www.repositorio.ufc.br/handle/riufc/19339>. Acesso em 23 de agosto de 2019.

DIAS, L. B. Simone de Beauvoir e a ontologia da ambiguidade. Reflexos, Fortaleza-CE, p. 66-79, 2015. Disponível em:

<https://www.academia.edu/14219856/Simone_de_Beauvoir_e_a_Ontologia_da_Ambiguidad e>. Acesso em 23 de agosto de 2019.

MOTTA, L. J. A relação entre ambiguidade, liberdade e condição humana em Simone de Beauvoir. Filogênese, Marília-SP, v. 11, p. 40-55, 2019. Disponível em: $<$ https://www.marilia.unesp.br/Home/RevistasEletronicas/FILOGENESE/a-relacao-entreambiguidade-liberdade-e-condicao-humana-em-simone-de-beauvoir.pdf $>$. Acesso em 20 de novembro de 2019.

RODRIGUES, C. Beauvoir com Sade: ética, ambiguidade e alteridade. Sapere aude, Belo Horizonte-MG, v. 3, n. 6, p. 234-249, 2012. Disponível em: <http://periodicos.pucminas.br/index.php/SapereAude/article/view/4624/4994>. Acesso em 23 de agosto de 2019.

SARTRE, J.-P. O existencialismo é um humanismo. São Paulo: Abril Cultural, 1978. (Coleção Os Pensadores)

O ser e o nada: ensaio de ontologia fenomenológica. Rio de Janeiro: Vozes, 2007. 